\title{
Work transition tips: Helping workers get the right information at the right time
}

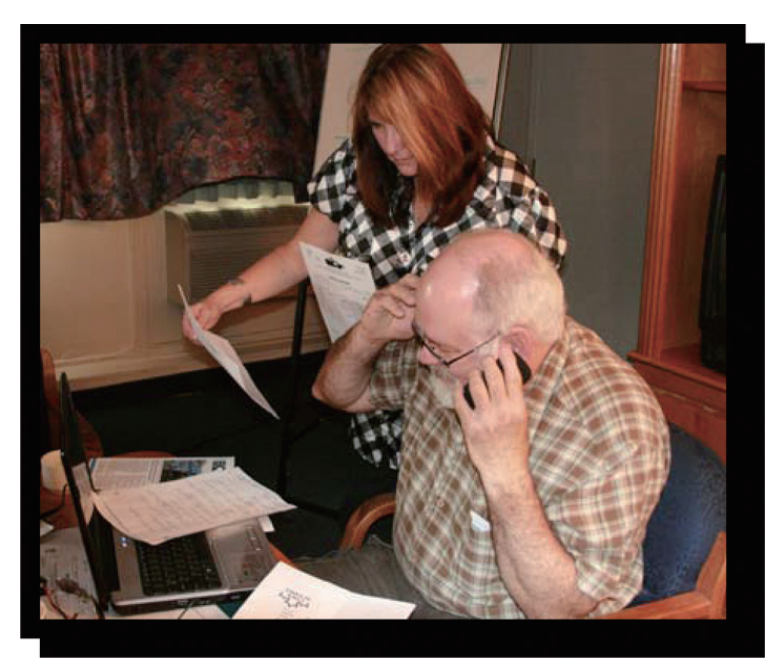

Trying to make sense of the vast amount of information needed to live with chronic pain or a chronic work injury/disability is overwhelming. People who play a role in helping persons with work injuries and chronic conditions sort out information and what it means to their daily and work life are people who counsel or advise a worker one-on-one, run support groups and health care professionals.

Most of these people do the best that they can to offer knowledge on health matters, coping with change, uncertainty, claims issues, and work issues. Unfortunately, most people who offer informational supports do not have any training in the theory or principles of knowledge transfer - how to make sure that people can use and understand the information they need. As a result, persons with chronic conditions and work loss of-

This Canadian Injured Workers Alliance KIT-Tip Sheet mini42010 was reprinted with the permission of the Canadian Injured Workers Alliance. This KITTip sheet developed by Dr. Lynn Shaw, Nathan Shaw, and CIWA IKT Advisory Committee 2010 and was reviewed and approved by CIWA Board in July 2010. ten get information at different times, mixed messages about what they need to know, do not always know what information is useful or how to use the information to make the best decisions and choices. Thus, the information workers need comes at the wrong time making it difficult to complete documentation on time, adjust their health and daily routines, to get better and to plan for going back to work.

Training in how to share knowledge for support groups and health professionals is needed to develop better practices and approaches to help workers use the information they need when they need it.

Research [1,2] suggests that persons with chronic conditions and work injuries:

- Struggle to use information as they do not get information on time.

- Become skeptical of the information they receive due to mixed messages and do not know what information is useful or correct.

- Persistently try to find the information need they talk with others and search the internet.

- Need to think about and plan for the present and the 'what ifs' such as the uncertainties of living with less income, and periods of good or ill health.

Research [1-4] suggests that information needs to be accessible, simple, and persons who have chronic conditions and work injuries must be given time to think on information so that they can use it. If you work with injured workers we encourage you to read, reflect, and use some of these steps to enhance what you currently do to help workers access the information they need. Once you have tried some of these we encourage you to talk with others and pass on what works!

Step 1 Provide Access to Information

- Ensure that information is available in different formats.

- Ensure that information is shared in a way that meets each person's learning needs. 
- Be open and honest about the information.

- Acknowledge that information is accurate to the best of your knowledge.

- Advocate for change when problems in the timing and accuracy of information are uncovered.

- Establish a set time each week to discuss information.

- Collaborate with others such as other support group leaders or health care professionals to ensure the worker receives timely and consistent information.

\section{Step 2 Provide Support to Understand}

- Ensure that simplest terms that are used.

- Avoid the use of culturally specific terms.

- Use one-on-one interactions to share information that is new or unfamiliar.

- Use multiple methods of sharing information in chunks when information is complex.

- Encourage use of different types of information, i.e. pictures and written.

- Help check the accuracy of information obtained from the internet.

- Review ways that a worker can ask for information they need from others.

- Provide opportunities to correct misinformation or misperceptions-ask a worker to tell you what they know.

- Provide sources of accurate information.

Step 3 Provide Support for Using Information

- Provide a safe place for workers to share information on an ongoing basis.

- Encourage a worker to think about new information and what it means to them.
- Encourage a worker to listen, talk, and share information with other injured workers and family.

- Encourage a worker to consider if information is of use for any short term or long term needs.

- Encourage a worker to consider ways they might help others with similar problems.

- Encourage a worker to do things that are important to them during recovery.

- Encourage a worker to integrate new information to build on what they know so that they can organize activities in their daily life to do the things they need and want to do and to manage their health conditions.

CIWA invites you to look further:

If you found this KITTIP ${ }^{1}$ sheet useful or wish to have more information about the research and other resources to assist you in helping injured workers please contact CIWA by email at ciwa@ vianet.ca

\section{References}

[1] Shaw, MacAhonic, Lindsay and Brake, (2009) Evaluating the support needs of injured work in managing occupational Transitions after injury. WORK, 32 477-490.

[2] Shaw, L., Pye, K., and Dodman, J. (2009) Client insights on knowledge use and access in return to work. Canadian Journal of Occupational Therapy, 76 (5) 359-367.

[3] Shaw, L., McDermid ,J., Kothari, A., Lindsay, R., Brake, P., Page, P., Argyle, C., Gagnon, C., and Knott, M. (2010) Knowledge brokering with injured workers: Perspectives of injured worker groups and health care professionals. WORK, 36.

[4] Shaw, L., Knott, M., Lindsay, R., Brake, P., Page P., Argyle, C., MacDermid, J., and Kothari, A. (2009) Opening doors to information for injured workers through knowledge exchange and research with consumer community groups. Occupational Therapy Now, July/August 11, 23-26. 